\title{
PERENCANAAN STRATEGI SISTEM DAN TEKNOLOGI INFORMASI PADA PT. TRIPURI MITRA NOBELINDO
}

\author{
Dewan Pelawi; Franky; Charles Willy; Bobby Irwanza \\ Jurusan Sistem Informasi, Fakultas Ilmu Komputer, Binus University \\ Jl. KH. Syahdan No. 9, Palmerah, Jakarta Barat 11480. \\ dewanpelawi2318@lecturer.binus.ac.id; dewanpelawi@yahoo.com
}

\begin{abstract}
Competitions faced by companies are some obstacles in achieving the business objectives to maintain the company's growth and survival. The use of information technology trend requires companies to use it in order to compete with competitors. Strategic planning of information system (IS) and information technology (IT) which refer to business strategy should be customized to the company's business processes. The process of finding a future application portfolio is preceded by the discovery of business strategy, IS/IT strategy managemen and IT strategy. The method used is the strategic planning of information system and information technology of Ward and Peppard. The discovery of business strategy through internal and external analysis of the company is done using tools: PEST, SWOT, Porter's five competitive model, Value chain, and CSF. The analysis of the current information systems helps determine the proposed IS and IT plan. The result achieved is strategic system plan and information technology that are appropriate to the company in achieving its business goals.
\end{abstract}

Keywords: planning, strategy, information systems, information technology

\begin{abstract}
ABSTRAK
Persaingan yang dihadapi perusahaan merupakan kendala untuk mencapai tujuan bisnis demi menjaga pertumbuhan dan kelangsungan hidup perusahaan. Trend penggunaan teknologi informasi menuntut perusahaan untuk menggunakannya agar mampu bersaing. Sistem Perencanaan strategi sistem informasi dan teknologi informasi yang mengacu pada strategi bisnis harus disesuaikan dengan proses bisnis perusahaan. Proses menemukan portfolio aplikasi masa depan didahului oleh penemuan strategi bisnis, strategi manajemen SI/TI dan strategi IT. Metode yang digunakan adalah perencaan strategi sistem informasi dan teknologi informasi Ward dan Peppard. Penemuan strategi bisnis dilakukan melalui analisis internal dan eksternal perusahaan yang dilakukan dengan tools seperti PEST, SWOT, lima model bersaing Porter, Value chain, dan CSF. Analisis terhadap sistem informasi yang ada saat ini membantu untuk menentukan rencana sistem informasi dan teknologi informasi yang akan diusulkan. Hasil yang dicapai adalah perencanaan strategi sistem dan teknologi informasi yang tepat bagi perusahaan dalam mencapai tujuan bisnisnya.
\end{abstract}

Kata kunci: perencanaan, strategi, sistem informasi, teknologi informasi. 


\section{PENDAHULUAN}

Sistem dan teknologi informasi merupakan tuntutan bagi perusahaan untuk diterapkan agar dapat bersaing dengan pesaingnya yang juga menggunakannya sebagai salah satu alat untuk mencapai keunggulan kompetitif. Sistem dan teknologi informasi harus sesuai dengan kebutuhan bisnis dan selaras dengan strategi dan tujuan perusahaan. Banyaknya aplikasi system informasi yang ada di pasar mengharuskan perusahaan merencanakan system dan teknologi yang akan digunakan. Adanya perencanaan strategi sistem dan teknologi informasi yang terencana dengan baik diharapkan membantu perusahaan dalam mencapai tujuan bisnis. Pencapaian tujuan tersebut harus didukung oleh semua bagian dalam perusahaan tersebut sehingga dapat menciptakan rantai nilai yang akan memberikan margin bagi perusahaan tersebut.

PT. Tripuri Mitra Nobelindo merupakan perseroan terbatas yang bergerak dibidang pendistribusian dan penjualan alat-alat listrik kepada pelanggan tertentu, distributor, retailer, dan end user. Perusahaan sudah menggunakan dukungan sistem informasi berupa pemanfaatan komputer untuk memproses transaksi bisnis dan menyimpan data. Adapun permasalahan yang dihadapi oleh perusahaan adalah belum adanya perencanaan system dan teknologi informasi, system informasi yang ada saat ini hanya sebatas membantu dalam transaksi penjualan. Perusahaan terdiri dari beberapa bagian yang harusnya saling terintegrasi untuk mencapai tujuan bisnis. Peran sistem dan teknologi informasi untuk membantu pencapaian tujuan perusahaan sangat dibutuhkan oleh karena itu, dipilihlah perusahaan tersebut sebagai objek penelitian.

\section{Tentang Perusahaan}

PT. Tripuri Mitra Nobelindo (TMN) yang beralamat di Perkantoran Tomang Tol Blok A-II/7, Jl. Angsana Raya, Kedoya, Jakarta berdiri tanggal 23 November 1992. Perusahaan ini bergerak dalam bidang pendistribusian dan penjualan barang-barang listrik pada khususnya dan juga barang kimia. Istilah barang listrik disini bukan mengenai elektronik yang kita kenal secara umum tapi sebagai distributor barang listrik untuk gedung, pabrik, proyek dan lain-lain. PT. Tripuri Mitra Nobelindo merupakan distributor merk Schyller dari Italia, Ebalta dari German, Nokian Capacitor dari Finlandia, TenT dari China, dan Powermat dari India. Untuk memperluas wilayah pemasaran dan penjualannya, perusahaan ini mendirikan cabang di Surabaya. Penjualan akan produk-produk perusahaan ini tidak saja di Jawa tetapi mencakup daerah lainnya seperti Sumatera, Kalimantan dan daerah-daerah lainnya.

\section{Ruang lingkup}

Ruang lingkup yang digunakan untuk penulisan ini meliputi analisis lingkungan eksternal bisnis yang sedang berjalan dengan menggunakan analisis PEST dan analisis lima faktor persaingan porter, analisis lingkungan internal bisnis dengan menggunakan analisis rantai nilai (value chain), analisis SWOT, EFAS, IFAS dan CSF, analisis lingkungan eksternal dan internal SI/TI dan hasilnya adalah sebuah perencanaan strategi sistem dan teknologi informasi pada PT. Tripuri Mitra Nobelindo.

\section{Kajian Pustaka}

\section{Strategi SI/IT}

Menurut Ward dan Peppard (2002, p.44), “Strategi teknologi informasi adalah strategi yang berfokus pada penetapan visi tentang bagaimana teknologi dapat mendukung dalam memenuhi kebutuhan informasi dan sistem dari sebuah informasi." Perusahaan membutuhkan perencanaan strategis untuk pengembangan sumber daya SI/TI dengan beberapa alasan yaitu membantu mengkomunikasikan masa depan perusahaan kepada pihak lain dalam organisasi, membantu para 
manajer bisnis dan ahli SI/TI membuat keputusan mengenai bagaimana SI/TI akan diarahkan untuk membantu bisnis perusahaan, dan hasil dari perencanaan SI/TI dapat membantu mengalokasikan sumber daya perusahaan yang ada ke proyek-proyek SI/TI yang penting dan bermanfaat bagi perusahaan (Jogiyanto, 2005, p.320).

Model kerangka kerja dari perencanaan strategi sistem dan teknologi informasi menurut Ward and Peppard (2002, p.154) (Gambar ) adalah sebagai berikut: (1) Inputs - sebagai masukan dalam perencanaan strategis sistem dan teknologi informasi, terdiri atas: The Internal Business Environment merupakan strategi bisnis yang digunakan pada masa sekarang, tujuan, sumber daya, proses, dan budaya organisasi serta nilai dari bisnis itu sendiri, The External Business Environment meliputi sisi politik, ekonomi, sosial, teknologi, industri, dan iklim kompetisi dimana perusahaan tersebut beroperasi, The Internal IS/IT Environment yaitu pandangan SI/TI terhadap bisnis pada masa sekarang ini, pengalaman perusahaan dalam bisnis, cakupan bisnis, dan kontribusinya terhadap pasar, kemampuan perusahaan, sumber daya dalam perusahaan dan infrastruktur teknologi yang digunakan. Aplikasi portfolio saat ini dari sistem yang berjalan dan sistem yang sedang dalam pengembangan atau belum dikembangkan tapi sudah direncanakan pada perusahaan dan The External IS/IT Environment meliputi perkembangan teknologi dan peluang yang ada, serta SI/TI yang digunakan oleh pihak lain terutama konsumen, pesaing dan pemasok; (2) Proses perencanaan strategi SI/TI, proses dimana informasi yang diperoleh, serta hasil analisis yang diperoleh dari inputs, akan diolah untuk menghasilkan outputs; (3) Outputs - merupakan hasil dari proses yang mencakup: (a) IS/IT management strategy yaitu elemen umum dari strategi yang akan diaplikasikan pada organisasi secara menyeluruh untuk memastikan konsistensi kebijakan berdasarkan kebutuhan; (b) Business IS Strategy, yaitu bagaimana setiap unit dapat memanfaatkan SI/TI dalam mencapai sasaran bisnisnya. Business IS Strategy mencakup portfolio aplikasi yang akan dikembangkan untuk setiap unit dan model bisnis; menjelaskan arsitektur informasi setiap unit dan (c) IT Strategy yaitu strategi dan kebijakan yang diterapkan untuk mengatur penggunaan teknologi dalam perusahaan dan mengatur sumber daya teknisi ahli; (4) Future application portfolio - rincian yang menjelaskan usulan aplikasi yang akan digunakan perusahaan dalam waktu ke depan, untuk mengintegrasikan setiap unit dari perusahaan dan menyesuaikan perkembangan teknologi dengan perkembangan perusahaan; (5) current application portfolio - rincian mengenai aplikasi sistem informasi yang diterapkan perusahaan saat ini, dengan melihat keuntungan dan kekuatan yang diperoleh dengan menggunakan aplikasi tersebut serta melihat dukungan aplikasi yang ada terhadap kegiatan operasional dan perencanaan strategi sistem dan teknologi informasi bagi perusahaan untuk menghadapi persaingan dan pasar pada saat sekarang ini.

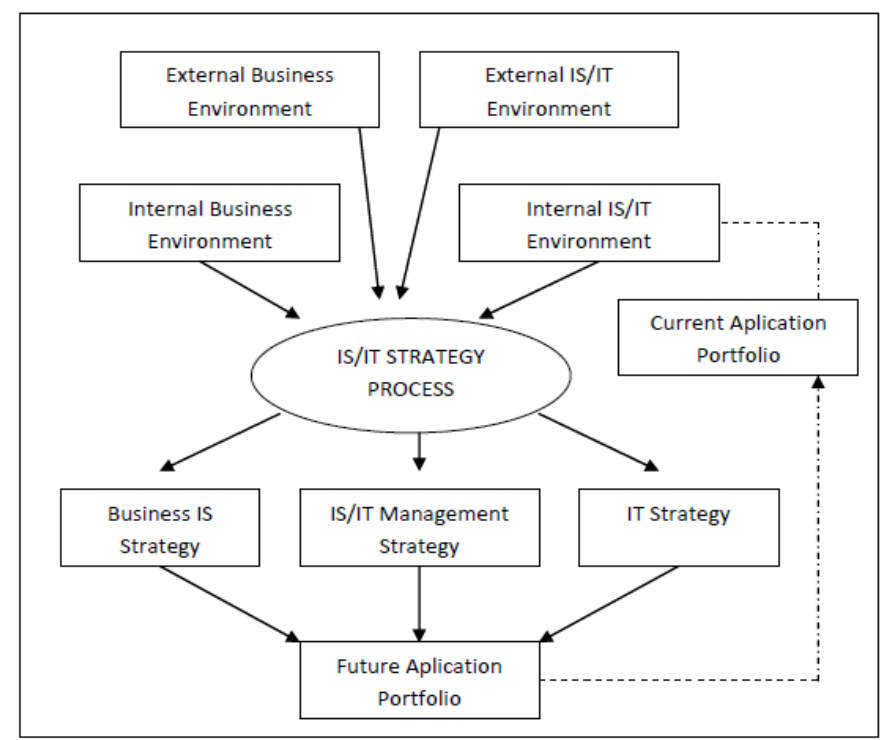

Gambar 2. Model kerangka kerja perencanaan strategi SI/TI (Ward dan Peppard, 2002, p.341). 


\section{Analisis Lima Model Persaingan Porter}

Adapun teknik analisis digunakan untuk memahami kondisi situasi pada lingkungan eksternal bisnis diantaranya adalah Analisis lima model persaingan Porter meliputi (1) analisis terhadap pendatang baru, (2) analisis terhadap barang pengganti, (3) analisis kekuatan tawar menawar terhadap pelanggan, (4) analisis kekuatan tawar menawar dengan supplier dan (5) analisis terhadap persaingan industri sejenis (Gambar 2).

\section{Analisis PEST (Politik, Ekonomi, Sosial, dan Teknologi)}

Analisis PEST adalah analisis terhadap faktor lingkungan eksternal bisnis yang meliputi bidang politik, ekonomi, sosial dan teknologi. PEST digunakan untuk menilai pasar dari suatu unit bisnis atau unit organisasi. Arah analisis PEST adalah kerangka untuk menilai sebuah situasi, dan menilai strategi atau posisi, arah perusahaan, rencana pemasaran atau ide. Dimana analisis ini dapat diambil suatu peluang atau ancaman baru bagi perusahaan yaitu faktor Politik meliputi kebijakan pemerintah, masalah-masalah hukum, serta mencakup aturan-aturan formal dan informal dari lingkungan dimana perusahaan melakukan kegiatan, faktor Ekonomi meliputi semua faktor yang mempengaruhi daya pembeli dari pelanggan dan mempengaruhi iklim dari bisnis suatu perusahaan. Contoh: pertumbuhan ekonomi, tingkat suku bunga, standar nilai tukar, tingkat inflasi, harga-harga produk dan jasa, faktor Sosial meliputi semua faktor yang dapat mempengaruhi kebutuhan dari pelanggan dan mempengaruhi ukuran dari besarnya pangsa pasar yang ada, faktor Teknologi meliputi semua hal yang dapat membantu dalam menghadapi tantangan bisnis dan mendukung efisiensi proses bisnis.

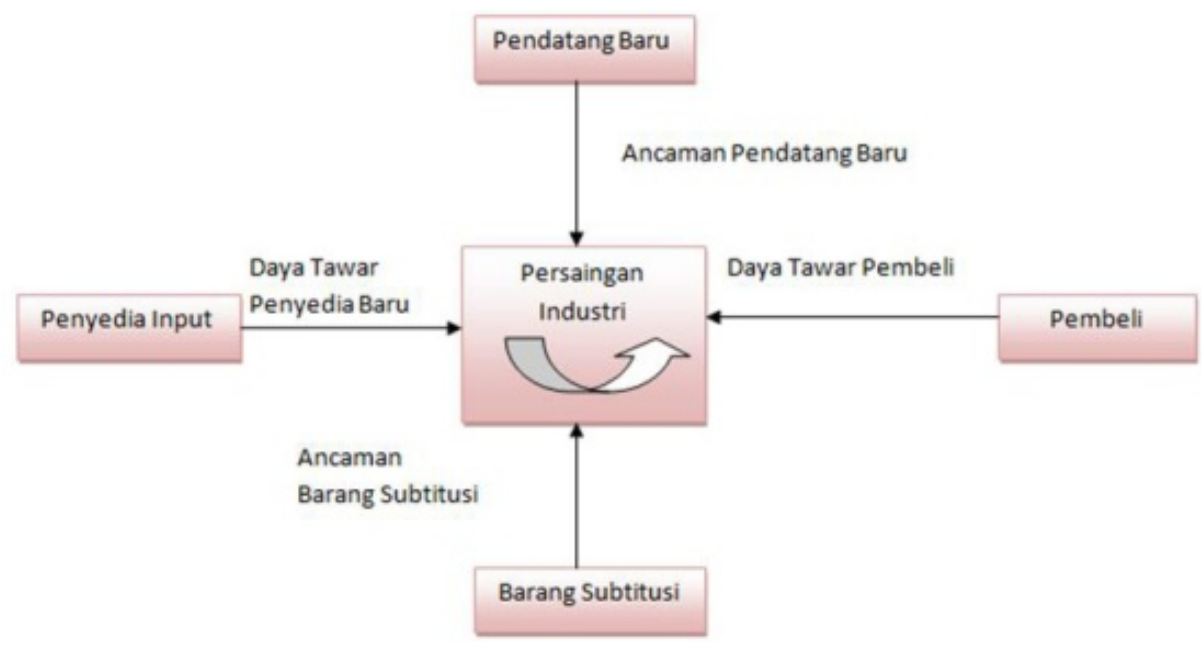

Gambar 3. Lima model persaingan Porter (Ward dan Peppard, 2002, p.95).

\section{Analisis Lingkungan Internal Bisnis}

Analisis lingkungan internal bisnis dari sebuah perusahaan digunakan untuk mengetahui strategi bisnis perusahaan pada saat ini, misi, dan visi perusahaan, aktivitas dan proses bisnis perusahaan, sumber daya yang dimiliki dan informasi yang dibutuhkan perusahaan. Adapun teknik teknik analisis yang digunakan dalam memahami kondisi situasi pada lingkungan internal bisnis diantaranya adalah: analisis rantai nilai (value chain) adalah kegiatan menganalisis kumpulan aktivitas yang dilakukan untuk merancang, memproduksi, memasarkan, mengantarkan dan mendukung produk atau jasa, dibedakan menjadi dua yaitu aktivitas utama (primary activities) pada perusahaan yang pada akhirnya memberikan kepuasan pada pelanggan. Aktivitas-aktivitas tersebut tidak hanya dilakukan 
dengan baik, tapi juga harus saling berhubungan dengan efektif jika keseluruhan performa bisnis hendak dioptimalkan. Aktivitas utama terdiri dari logistik dalam, operasi, logistik keluar, pemasaran, dan pelayanan. Kedua adalah aktivitas pendukung (Support Activities) yang mendukung aktiviatas utama yang terdiri dari berbagai fungsi, yaitu kelengkapan infrastruktur, manajemen SDM, pengadaan barang, dan pengembangan teknologi.

\section{Analisis SWOT}

Analisis SWOT membandingkan antara faktor eksternal peluang dan ancaman dengan faktor internal kekuatan dan kelemahan.Analisis ini terbagi atas empat komponen dasar, yaitu: strength (kekuatan) merupakan kekuatan dari organisasi, weakness (kelemahan) merupakan kelemahan dari organisasi, opportunity (peluang) merupakan peluang dari luar organisasi dan memberikan peluang kepada organisasi untuk berkembang dimasa mendatang dan threat (ancaman) merupakan ancaman dari luar bagi organisasi dan dapat mengancam eksistensi organisasi dimasa mendatang.

\section{Analisis Ekternal dan Internal SI/TI}

Analisis eksternal SI/TI bertujuan untuk mendapatkan pengetahuan tentang peluang-peluang baru dalam penggunaan SI/TI dan tidak hanya terbatas pada peluang untuk mengimplementasikan teknologi namun juga dapat berupa peluang untuk menggunakan teknologi yang sudah ada dengan cara yang lebih hemat dan tepat dalam penggunaannya atau peluang untuk menggunakan teknologi dengan cara lain yang tidak terpikirkan sebelumnya. Inti dari analisis ini adalah untuk dapat menyediakan informasi yang menyeluruh tentang eksternal SI/TI untuk digunakan sebagai salah satu bentuk masukan dalam bentuk proses perencanaan strategi SI/TI (Ward dan Peppard, 2002, p203204). Analisis lingkungan internal SI/TI mengetahui pandangan SI/TI terhadap bisnis pada masa sekarang ini, pengalaman perusahaan dalam bisnis, cakupan bisnis dan kontribusinya terhadap pasar, kemampuan perusahaan, sumber daya didalam perusahaan dan infrastruktur teknologi yang digunakan. Aplikasi portfolio saat ini dari sistem yang berjalan dan sistem yang sedang dalam pengembangan (Ward dan Peppard, 2002, p.153). Portfolio aplikasi adalah cara untuk membawa bersama sistem informasi yang telah ada, yang direncanakan dan potensial kemudian menilai kontribusi bisnisnya, umumnya berupa matrik 2x2, yang merupakan metode yang sangat populer untuk menjelaskan dampak dari variabel yang tidak berkaitan namun saling mempengaruhi. Dalam portfolio aplikasi, sebuah aplikasi dapat dikategorikan sebagai strategic, high potential, key operational dan support tergantung dari peranannya dalam mendukung strategi bisnis perusahaan, baik saat ini maupun disaat mendatang.

Hasil atau output dari sebuah proses perencanaan SI/TI adalah gabungan dari hasil yang bersifat hard dan soft. Hasil yang bersifat hard adalah dokumen yang mendefinisikan strategi-strategi dan rencana-rencana, dapat juga berisi materi yang berhubungan dengan komputer, matrik-matrik dan model analisis. Sedangkan hasil yang bersifat soft berhubungan dengan faktor manusia seperti standar keahlian yang dibutuhkan dan lainnya (Ward dan Peppard, 2002, p.162).

\section{METODE}

Metode yang diterapkan dalam menganalisis sistem yang sedang berjalan pada PT. Tripuri Mitra Nobelindo adalah: (1) metode pengumpulan data dengan melakukan wawancara dan survei dengan pihak-pihak yang terkait atas sistem yang sedang berjalan dengan cara melakukan observasi langsung ke perusahaan, dan studi pustaka dengan mencari informasi-informasi yang dibutuhkan dan diperlukan dengan cara membaca buku-buku, melakukan searching di internet dan sumber-sumber lainnya untuk mengetahui teori-teori lebih dalam sehingga dapat membantu menganalisis masalah- 
masalah yang terjadi pada sistem yang sedang berjalan; (2) metode analisis menggunakan analisis value chain, analisis SWOT, analisis CSF (Critical Success Factor) yang digunakan untuk mengidentifikasi area kunci di mana segala sesuatu harus berjalan dengan benar bagi bisnis untuk tumbuh, analisis lima faktor persaingan Porter, penyusunan kerangka kerja perencanaan strategi sistem dan teknologi informasi sesuai dengan yang dibutuhkan PT. Tripuri Mitra Nobelindo, analisis PEST (Politik, Ekonomi, Sosial, dan Teknologi) menurut Ward dan Peppard, analisis portfolio McFarlan (Strategic, High Potential, Key Operational, dan Support), dan analisis lingkungan internal dan eksternal SI/TI; (3) Perencanaan Strategi SI/TI menggunakan perencanaan strategi bisnis, perencanaan IS/IT management strategy, dan perencanaan IT strategy.

\section{HASIL DAN PEMBAHASAN}

\section{Analisis Ekternal Perusahaan}

Tabel 1

Analisis PEST Perusahaan

\begin{tabular}{lll}
\hline \multicolumn{1}{c}{ Model } & \multicolumn{1}{c}{ Relevansi } & \multicolumn{1}{c}{ Strategi } \\
\hline Politik & $\begin{array}{l}\text { Undang - undang } \\
\text { Pajak } \\
\text { Peraturan daerah }\end{array}$ & $\begin{array}{l}\text { Dapat memahami dan menyesuaikan undang - undang, } \\
\text { pajak, dan peraturan daerah untuk diadaptasikan dalam } \\
\text { bisnis perusahaan. }\end{array}$ \\
\hline \multirow{2}{*}{ Ekonomi } & $\begin{array}{l}\text { Perubahan harga valuta asing } \\
\text { Perubahan harga barang }\end{array}$ & $\begin{array}{l}\text { Mendapatkan informasi yang up to date mengenai situasi } \\
\text { kondisi keuangan global untuk menentukan strategi } \\
\text { harga. }\end{array}$ \\
\hline \multirow{2}{*}{ Sosial } & $\begin{array}{l}\text { Hubungan dengan pemasok } \\
\text { Pelayanan kepada pelanggan } \\
\text { Kesejahteraan karyawan }\end{array}$ & $\begin{array}{l}\text { Membina hubungan yang baik dengan pelanggan, } \\
\text { pemasok, dan karyawan, serta semua pihak yang } \\
\text { berkaitan dengan bisnis perusahaan. }\end{array}$ \\
\hline \multirow{2}{*}{ Teknologi } & $\begin{array}{l}\text { Perkembangan SI / TI } \\
\text { Memaksimalkan penggunaan SI / TI } \\
\text { untuk mendukung proses bisnis }\end{array}$ & $\begin{array}{l}\text { Mengikuti perkembangan teknologi secara up to date } \\
\text { yang disesuaikan dengan kebutuhan perusahaan. }\end{array}$ \\
\hline
\end{tabular}

Tabel 2

Analisis Lima Faktor Persaingan Porter

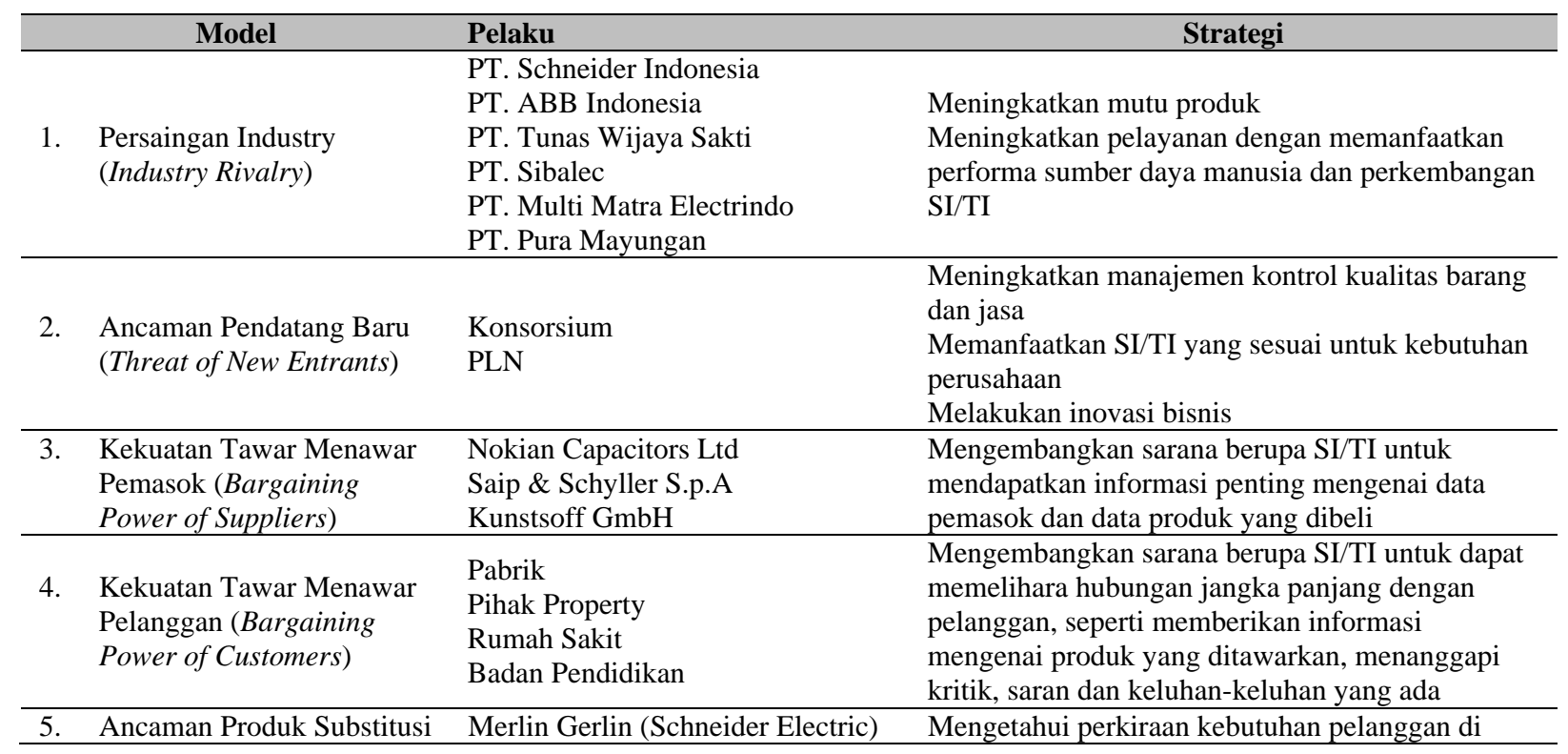




\begin{tabular}{lll}
\hline (Threats of Substitute & ABB Capacitors & masa kini dan masa yang akan datang, sehingga \\
Products) & Hager & dapat diciptakan inovasi baru dan meningkatkan \\
& Legrand & \\
& Socomec & \\
Axle & \\
& T\&B & \\
\hline
\end{tabular}

Untuk lebih jelasnya, hasil analisis ini dirangkum pada Gambar 4 berikut:

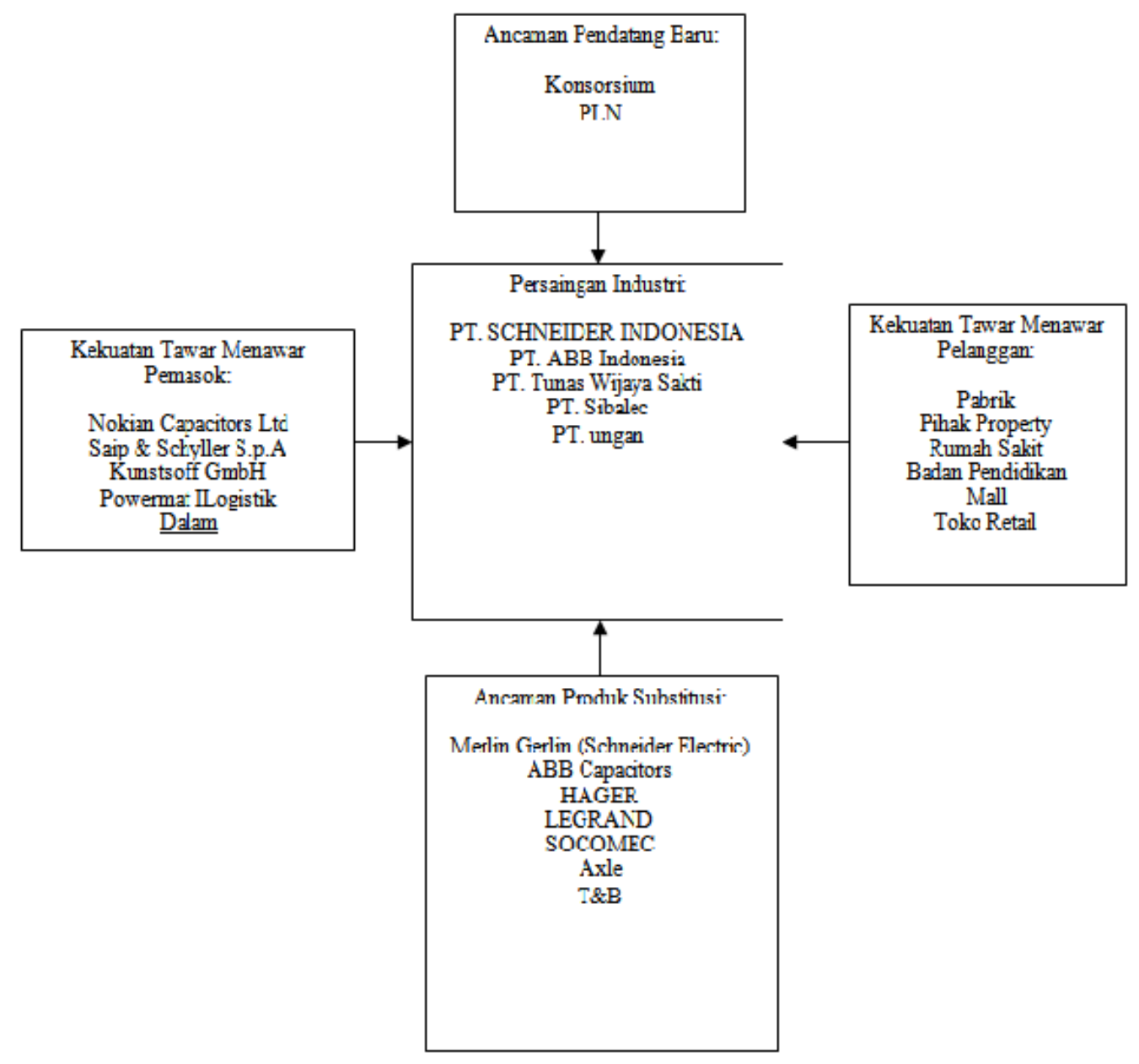

Gambar 4. Lima faktor persaingan Porter.

\section{Analisis Lingkungan Internal Bisnis Perusahaan}

Analisis terhadap Lingkungan Internal Bisnis Perusahaan mencakup Analisis Rantai Nilai (Value Chain) Perusahaan, SWOT, IFAS, EFAS, CSF.

\section{Analisis Rantai Nilai (Value Chain) Perusahaan}

Value chain terdiri dari dua kategori, yaitu aktivitas utama dan aktivitas pendukung. Aktivitas utama terdiri dari logistik dalam, operasi, logistik keluar, pemasaran, dan pelayanan. Aktivitas pendukung terdiri dari kelengkapan infrastruktur, manajemen sumber daya manusia, pengembangan teknologi, dan pengadaan barang. Berikut ini adalah gambar dan uraian value chain dari PT. Tripuri Mitra Nobelindo (Gambar 5): 


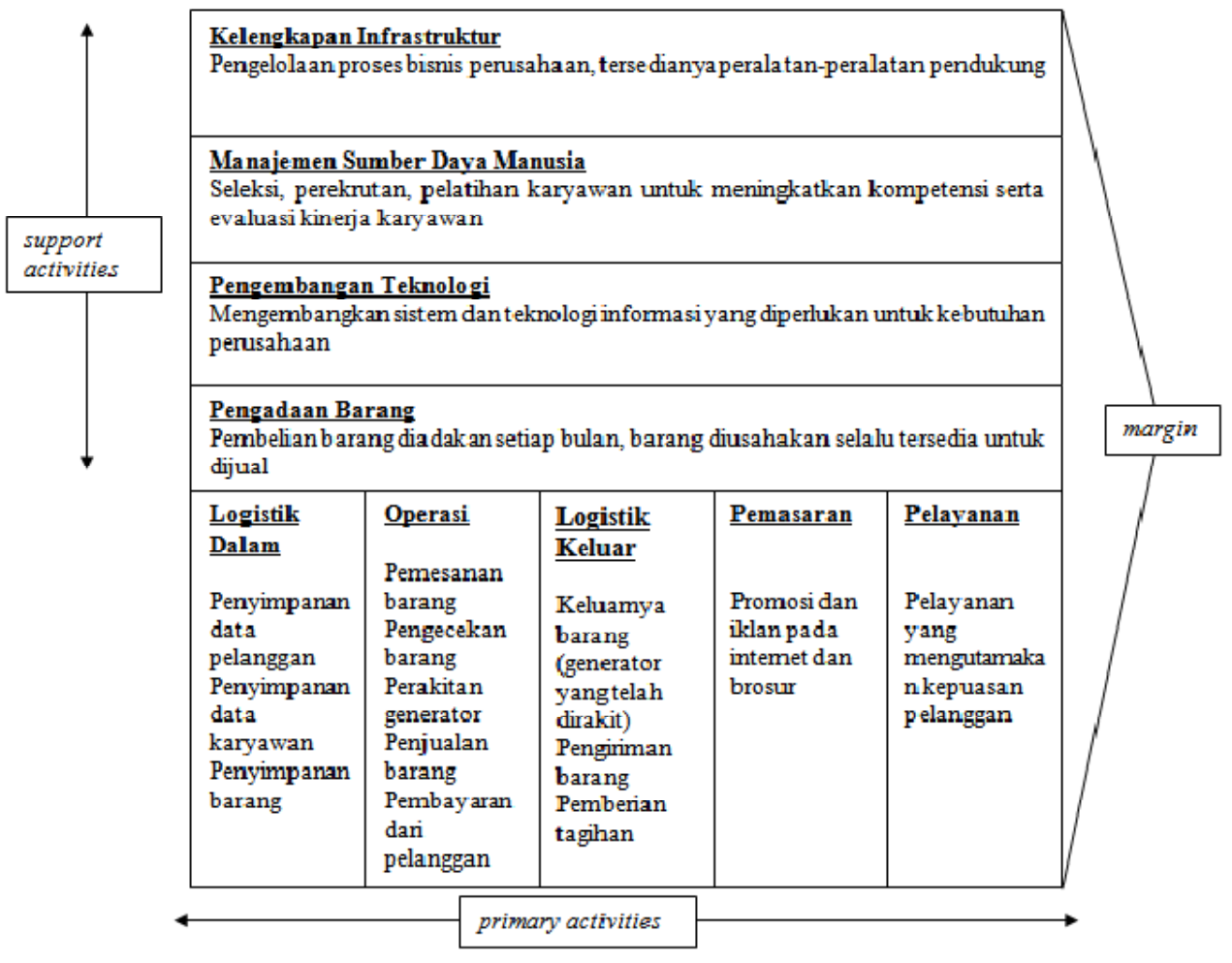

Gambar 5. Analisis rantai nilai (value chain) perusahaan.

\section{Dari analisis value chain dapat disimpulkan (Tabel 3):}

Tabel 3

Kesimpulan Analisis Value Chain

\begin{tabular}{|c|c|c|}
\hline Model & Aktivitas & Strategi \\
\hline \multicolumn{3}{|l|}{ Aktivitas Pendukung } \\
\hline $\begin{array}{l}\text { Kelengkapan } \\
\text { Infrastruktur }\end{array}$ & $\begin{array}{l}\text { Pengelolaan proses bisnis } \\
\text { perusahaan, tersedianya peralatan- } \\
\text { peralatan pendukung }\end{array}$ & $\begin{array}{l}\text { Perusahaan perlu mengembangkan infrastruktur baru berupa } \\
\text { arsitektur jaringan yang didalamnya meliputi pengembangan } \\
\text { aplikasi dan pengadaan server untuk pengaksesan dan } \\
\text { pengintegrasian data yang lebih cepat }\end{array}$ \\
\hline $\begin{array}{l}\text { Manajemen } \\
\text { Sumber Daya } \\
\text { Manusia }\end{array}$ & $\begin{array}{l}\text { Seleksi, perekrutan, pelatihan } \\
\text { karyawan untuk meningkatkan } \\
\text { kompetensi serta evaluasi kinerja } \\
\text { karyawan }\end{array}$ & $\begin{array}{l}\text { Kegiatan seleksi, perekrutan, dan pelatihan karyawan } \\
\text { dilakukan oleh Kepala Bagian dan Wakil Direktur dari masing- } \\
\text { masing bagian }\end{array}$ \\
\hline $\begin{array}{l}\text { Pengembangan } \\
\text { Teknologi }\end{array}$ & $\begin{array}{l}\text { Mengembangkan sistem dan } \\
\text { teknologi informasi yang diperlukan } \\
\text { untuk kebutuhan perusahaan }\end{array}$ & $\begin{array}{l}\text { Perusahaan harus mengembangkan website dinamis seperti } E \text { - } \\
\text { commerce sebagai media pemasaran } \\
\text { Dibutuhkan aplikasi untuk mengolah data transaksi, pembuatan } \\
\text { laporan untuk pengambilan keputusan eksekutif dan } \\
\text { pemeliharaan hubungan jangka panjang dengan pelanggan }\end{array}$ \\
\hline Pengadaan Barang & $\begin{array}{l}\text { Aktivitas pembelian barang yang } \\
\text { diadakan setiap bulan } \\
\text { Barang diusahakan selalu tersedia } \\
\text { untuk dijual. }\end{array}$ & $\begin{array}{l}\text { Memerlukan suatu aplikasi yang dapat mengelola transaksi } \\
\text { pembelian barang, sehingga eksekutif dapat membuat } \\
\text { keputusan untuk pengadaan barang berikutnya }\end{array}$ \\
\hline \multicolumn{3}{|l|}{ Aktivitas Utama } \\
\hline Logistik Dalam & $\begin{array}{l}\text { Penyimpanan data pelanggan } \\
\text { Penyimpanan data karyawan } \\
\text { Penyimpanan barang yang diterima } \\
\text { dari supplier }\end{array}$ & $\begin{array}{l}\text { Dibutuhkan suatu sistem informasi untuk mendukung logistik } \\
\text { dalam agar data-data yang ada dapat diolah dan diintegrasikan } \\
\text { secara cepat dan akurat untuk kelanjutan proses aktivitas bisnis }\end{array}$ \\
\hline
\end{tabular}




\begin{tabular}{lll}
\hline Operasi & $\begin{array}{l}\text { Pemesanan barang } \\
\text { Pengecekan barang } \\
\text { Penjualan barang } \\
\text { Pembayaran dari pelanggan }\end{array}$ & $\begin{array}{l}\text { Dibutuhkan suatu sistem informasi untuk memudahkan } \\
\text { pengolahan data transaksi, sehingga keseluruhan proses operasi } \\
\text { dapat berjalan lebih optimal }\end{array}$ \\
\hline logistik Keluar & $\begin{array}{l}\text { Keluarnya barang } \\
\text { Pengiriman barang } \\
\text { Pemberian tagihan } \\
\text { Retur kepada pemasok jika ada } \\
\text { barang rusak }\end{array}$ & $\begin{array}{l}\text { Diperlukan suatu sistem informasi untuk mendukung aktivitas } \\
\text { logistik keluar, sehingga pengolahan data transaksi keluarnya } \\
\text { barang, pengiriman barang dan pemberian tagihan dapat } \\
\text { terkelola dengan lebih baik }\end{array}$ \\
& Promosi dan iklan pada internet dan \\
& brosur & $\begin{array}{l}\text { Perusahaan perlu menerapkan suatu media interaktif sebagai } \\
\text { sarana untuk pemasaran. E-commerce merupakan solusi yang } \\
\text { tepat untuk mencapainya karena berbisnis secara online } \\
\text { Pemasaran }\end{array}$ \\
& Fokus kepada kepuasan pelanggan tren terdepan saat ini \\
\hline Pelayanan & $\begin{array}{l}\text { Diperlukan sistem informasi yang dapat membantu perusahaan } \\
\text { dalam menjaga dan menjalin komunikasi yang baik dengan } \\
\text { pelanggan untuk jangka panjang, yaitu penerapan Electronic } \\
\text { Customer Relationship Management (E-CRM) }\end{array}$ \\
\hline
\end{tabular}

Tabel 4

Analisis SWOT Perusahaan

\section{IFAS}

Strength (S)

(S1) Menjadi agen tunggal untuk penjualan alat-alat listrik yang khusus pada merk Nokian Capacitors, Schyller, Powermat, Ebalta dan Tent.

(S2) Mempunyai hubungan yang baik dengan banyak mitra bisnis dalam usaha ini.

(S3) Memiliki pelayanan yang professional dan jaminan kualitas barang yang bermutu sehingga loyalitas pelanggan tetap terjaga.

(S4) Memiliki pengalaman hampir dua puluh tahun sehingga perusahaan sangat berkompeten dalam bidang ini.
Weakness (W)

(W1) Infrastruktur jaringan yang belum diimplementasikan untuk pertukaran data antar kantor cabang,

(W2) Website yang digunakan masih bersifat statis dan menumpang.

(W3) Aplikasi yang digunakan saat ini masih mempunyai suatu kekurangan dalam fungsi dan perannya terhadap perusahaan yang membutuhkan suatu fitur untuk membantu dalam mengambil keputusan manajerial \& eksekutif.

(W4) Memiliki kesulitan dalam melayani dan memenuhi kebutuhan pelanggan yang berada jauh dari lokasi kantor pusat.
EFAS

Opportunities (O)

(O1) Memperluas pangsa pasar di Indonesia

(O2) Semakin banyaknya pemesanan akan alat-alat listrik untuk kebutuhan pembangunan di masa yang akan datang.

(O3) Adanya kemungkinan bekerjasama dengan mitra bisnis baru.

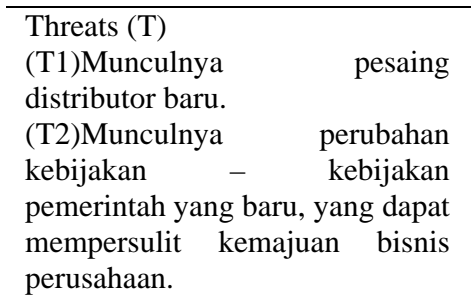

(T3)Kemungkinan berkurangnya mitra bisnis dan pelanggan.

\section{Strategi SO}

(S1-O1)Menambahkan produk baru, mitra bisnis baru, pelanggan baru dengan melakukan ekspansi untuk dapat meningkatkan keuntungan perusahaan.

(S1-O2) Dengan menjadi agen tunggal dan semakin banyaknya permintaan barang, maka dibutuhkan aplikasi untuk mendukung keputusan.

Strategi ST

(S2-T1)Mempererat hubungan dengan mitra bisnis dan bekerja sama untuk memunculkan strategi serta inovasi bisnis baru.

(S4-T2)Mematuhi mengadaptasikan semua kebijakan pemerintah dengan pengalaman yang ada, agar bisnis berjalan dengan baik.

\section{Strategi WO}

(W2-O2) Membuat website baru berbasis CMS dan E-CRM yang dapat memperkenalkan perusahaan dan produknya pada pelanggan baru.

(W4-O1) Membuka cabang di berbagai wilayah di Indonesia untuk dapat menangani pelayanan pelanggan di kantor cabang

\section{Strategi WT}

(W4-T3) Mendapatkan pelanggan dan mitra bisnis baru serta memelihara hubungan pelanggan dan mitra bisnis lama dengan meningkatkan kualitas pelayanan dan profesionalisme bisnis tanpa batasan wilayah. 
Tabel 5

Analisis Matriks Faktor Strategi Internal IFAS

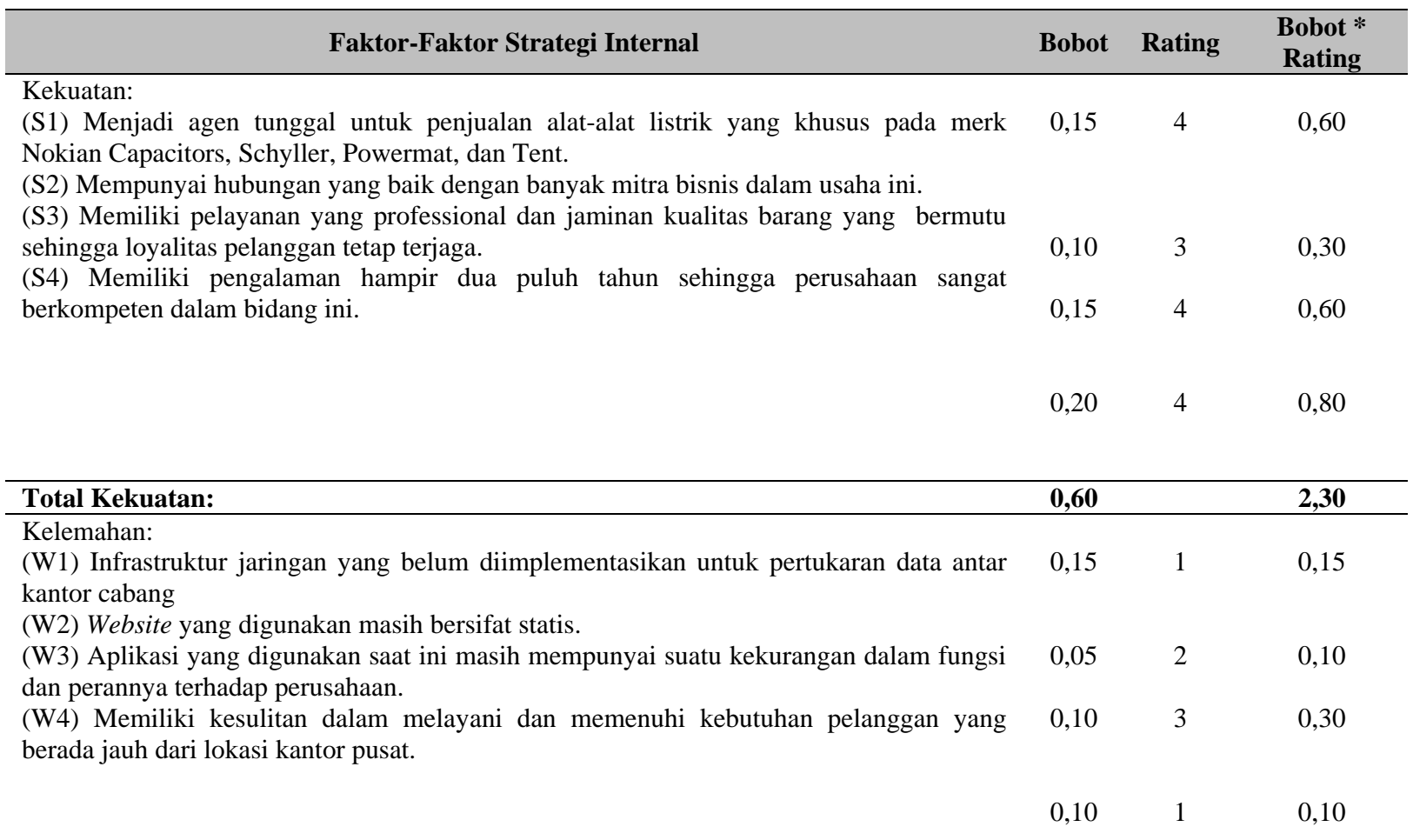

\begin{tabular}{llr}
\hline Total Kelemahan: & $\mathbf{0 , 4 0}$ & 0,65 \\
\hline Total & 1,00 & 2,95 \\
\hline
\end{tabular}

$\begin{array}{cl}\text { Perhitungan IFAS: Kekuatan } & : 2,30 \\ \text { Kelemahan } & : 0,65 \\ \text { Titik X (internal) } & =\text { kekuatan - kelemahan } \\ & =1,65\end{array}$

Tabel 6

Analisis Matriks Faktor Strategi Eksternal EFAS

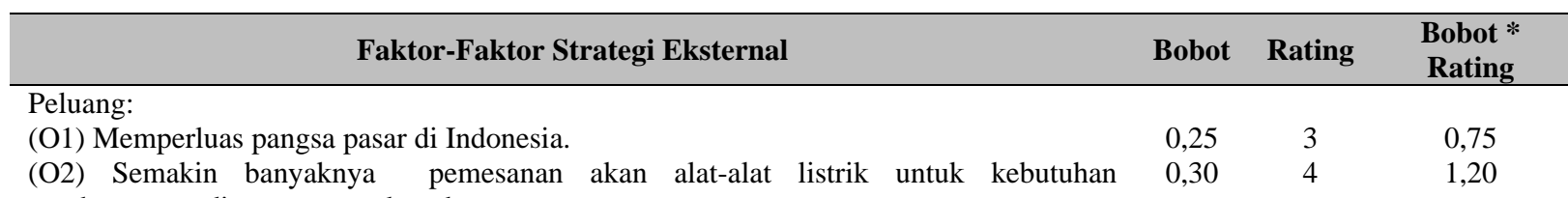

pembangunan di masa yang akan datang.

(O3) Adanya kemungkinan bekerjasama dengan mitra bisnis baru.

\begin{tabular}{lrr} 
& 0,05 & 2 \\
\hline Total Peluang: & $\mathbf{0 , 6 0}$ & \\
\hline Ancaman: & & \\
(T1) Munculnya pesaing baru. & 0,15 & 2 \\
(T2) Munculnya perubahan kebijakan-kebijakan & 0,30 & 2 \\
mempersulit kemajuan bisnis perintah yang baru, yang dapat & 0,05 & 0,10
\end{tabular}

mempersulit kemajuan bisnis perusahaan.

(T3) Kemungkinan berkurangnya mitra bisnis dan pelanggan.

\begin{tabular}{lrrr} 
& & 0,20 & 1 \\
\hline Total Ancaman: & & $\mathbf{0 , 4 0}$ & $\mathbf{0 , 6 0}$ \\
\hline Total & & $\mathbf{1 , 0 0}$ & $\mathbf{2 , 6 5}$ \\
\hline & Perhitungan EFAS: Peluang & $: 2,05$ &
\end{tabular}




$$
\begin{gathered}
\text { Titik Y (eksternal) }=\text { Peluang }- \text { Ancaman } \\
=1,45
\end{gathered}
$$

Berikut ini adalah kurva IFAS-EFAS analisis SWOT pada PT. Tripuri Mitra Nobelindo (Gambar 6).

\section{Analisis Lingkungan Eksternal SI/TI Perusahaan}

PT. Tripuri Mitra Nobelindo selama hampir 20 telah memiliki reputasi bisnis, kegiatan operasional dan manajemen yang baik, sehingga pemenuhan kebutuhan pelanggan dapat terpenuhi. Semua hal tersebut sepenuhnya masih mengandalkan tenaga karyawan, tetapi peran teknologi SI/TI yang dapat menunjang seluruh proses bisnis perusahaan belum dimanfaatkan secara optimal. Perkembangan teknologi sekarang ini dapat mempengaruhi kegiatan bisnis perusahaan, misalnya pemanfaatan waktu dan tenaga secara lebih efektif dan efisien. Dengan demikian, mengikuti perkembangan dan memanfaatkan SI/TI yang tepat guna bagi perusahaan, khususnya website, aplikasi dan jaringan akan menjadi solusi yang baik untuk meningkatkan kinerja, sehingga dapat memajukan kesuksesan perusahaan baik dalam bersaing maupun dalam kelancaran proses bisnis.

\section{Analisis Lingkungan Internal SI/TI Perusahaan}

Lingkungan Internal SI/TI Perusahaan saat ini sudah menggunakan SI/TI di semua divisi, tetapi belum maksimal. Aplikasi yang digunakan oleh oleh divisi Finance \& Accounting dan bagian komputerisasi saat ini adalah software Accurate, yang merupakan software akuntansi untuk mengkalkulasi penjualan, pembelian dan lain-lain yang berhubungan dengan keuangan yang dipakai oleh divisi Finance \& Accounting dan bagian komputerisasi. Berikut spesifikasi software dan hardware yang mereka milik (Tabel 7)

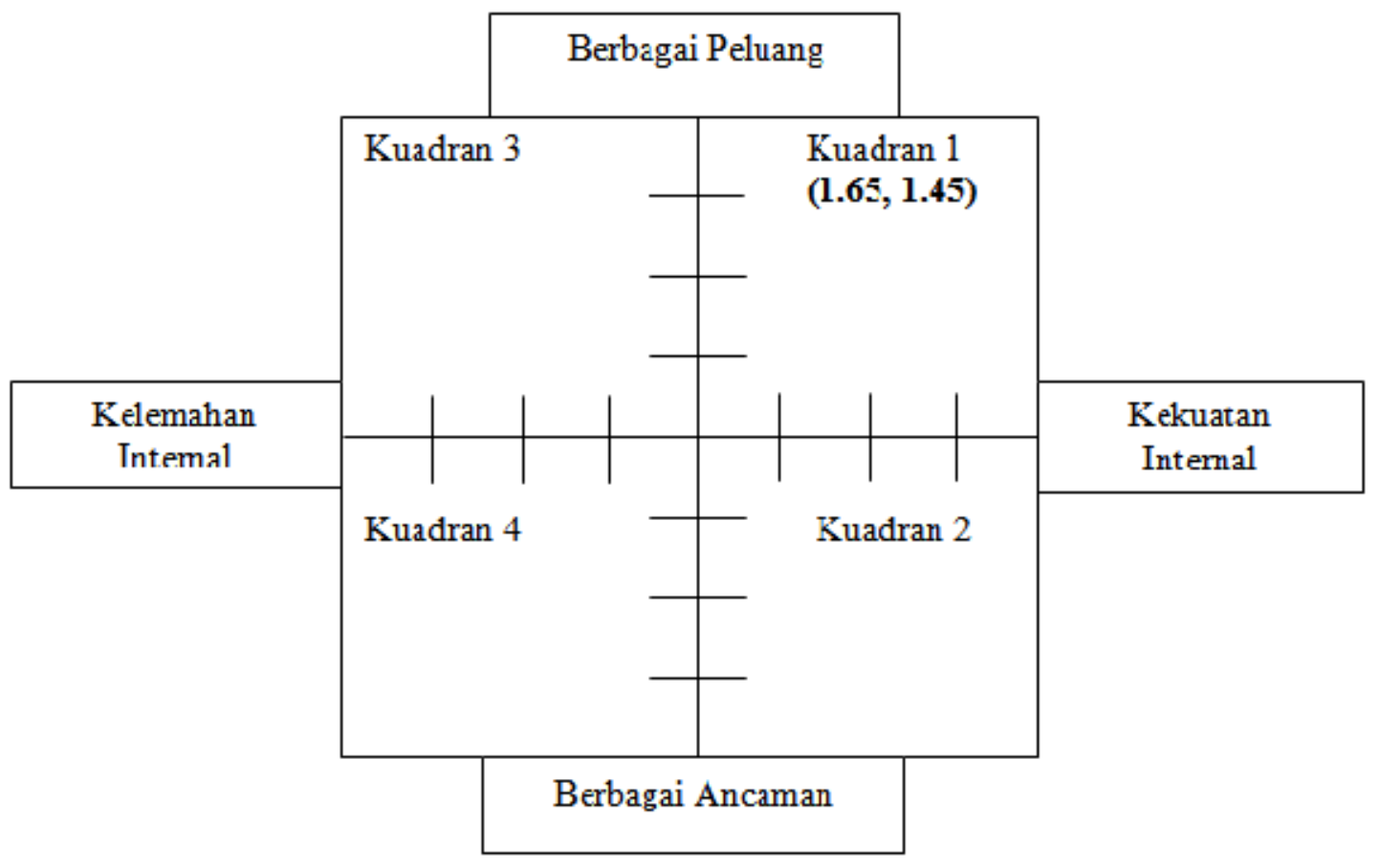

Gambar 6. Kurva IFAS-EFAS analisis SWOT pada PT. Tripuri Mitra Nobelindo. 
Tabel 7

Spesifikasi Hardware dan Software

\begin{tabular}{llc}
\hline Hardware & \multicolumn{1}{c}{ Keterangan } & Jumlah \\
\hline Desktop & PC Desktop untuk Eksekutif & 3 \\
& Processor Intel Dual Core @ 2.0 Ghz & \\
& Memory RAM 2 GB DDR2 & \\
& Harddisk 320 GB & \\
& Monitor LCD 17” & 3 \\
& LAN Card & \\
\hline Laptop & Laptop untuk Eksekutif & \\
& Processor Intel Dual Core @ 2.0 Ghz & \\
& Memory RAM 2 GB DDR2 & \\
& Harddisk 320 GB & \\
& LCD 14,1” & \\
\hline Desktop & PC Desktop untuk Staff & \\
& Processor Intel Dual Core @ 2.0 Ghz & \\
& Memory RAM 1 GB DDR2 & 1 \\
& Harddisk 250 GB & \\
\hline & Monitor CRT 15” & \\
& LAN Card & \\
\hline Others & Printer & \\
& UPS & \\
& Switch / Hub & \\
& Modem Router & \\
& Genuine Microsoft Windows XP (untuk PC Staff) \\
Software & Genuine Microsoft Windows 7 (untuk Laptop dan PC Eksekutif) & \\
& Genuine Microsoft Office 2007 & \\
& Genuine Kaspersky Antivirus (untuk Laptop dan PC Eksekutif) & \\
& AVG Antivirus Free (untuk PC Staff) & \\
& Aplikasi Keuangan Accurate & \\
\hline
\end{tabular}

\section{Arsitektur Jaringan Perusahaan}

Berikut ini adalah infrastruktur jaringan pada PT.TMN yang sedang berjalan (Gambar 7):

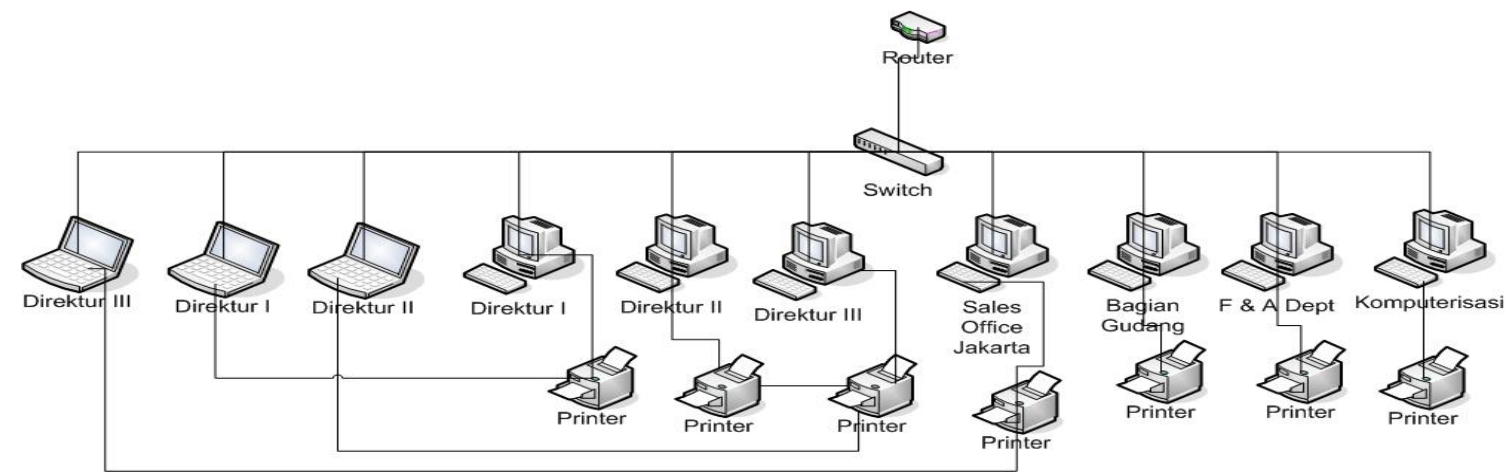

Gambar 7. Infrastruktur jaringan pada PT.TMN.

\section{Analisis Portfolio Aplikasi (McFarlan) saat ini}

Untuk menilai aplikasi yang digunakan perusahaan, apakah masuk dalam kategori high potential, strategic, key operational atau support sesuai dengan kontribusinya terhadap perusahaan, digunakan aplikasi portfolio McFarlan. Berikut ini adalah aplikasi portfolio pada PT.TMN yang sedang berjalan (Tabel 8): 
Tabel 8

Analisis Portfolio Aplikasi (McFarlan) saat ini

\begin{tabular}{llc}
\hline Strategic & & High Potential \\
\hline & & \\
\hline & Software & Microsoft Office \\
& Accounting & 2007 \\
& Accurate &
\end{tabular}

\section{Usulan Perencanaan Strategi Sistem Dan Teknologi Informasi}

Perencanaan strategi bisnis jangka panjang perusahaan yang diusulkan: (1) Menyediakan suatu sarana teknologi informasi dan akses komunikasi yang mudah dan cepat; (2) Menyediakan akses informasi, pemasaran dan transaksi jual beli berupa media elektronik; (3) Menyediakan suatu media untuk menjalin dan menjaga hubungan jangka panjang dengan pelanggan; (4) Mempermudah pengolahan sumber daya data, pencatatan, perhitungan dan histori transaksi; (5) Memberikan akses yang mudah, cepat dan akurat kepada eksekutif dalam mendapatkan informasi; (6) Mengintegrasikan aplikasi-aplikasi yang ada dalam perusahaan.

Sedangkan usulan untuk strategi SI/TI adalah: (1) Merancang arsitektur jaringan dan aplikasi yang baru pada PT. Tripuri Mitra Nobelindo; (2) Penerapan aplikasi E-commerce pada perusahaan; (3) Penerapan aplikasi Electronic Customer Relationship Management (E-CRM); (3) Penerapan aplikasi system informasi management; (4) Penerapan aplikasi Executive Information System (EIS); (6) Penerapan Enterprise Application Integration (EAI). (Tabel 9).

Di bawah ini adalah daftar usulan aplikasi berikut teknologi, estimasi waktu dan manfaatnya

Tabel 9

Detil Usulan Aplikasi

\begin{tabular}{|c|c|c|c|}
\hline Aplikasi & Teknologi & $\begin{array}{c}\text { Estimasi } \\
\text { Waktu }\end{array}$ & Manfaat \\
\hline $\begin{array}{l}\text { E-commerce } \\
\text { (electronic } \\
\text { commerce) }\end{array}$ & $\begin{array}{l}\text { Website berbasis CMS, web browser } \\
\text { (Google Chrome, Internet Explorer), } \\
\text { web dengan bahasa pemrograman } \\
\text { PHP, Apache sebagai web server, dan } \\
\text { MySQL sebagai database. } \\
\text { Sistem operasi: Windows } 7 \\
\text { Professional, Windows Server } \\
\text { Standard 2008. } \\
\text { Spesifikasi hardware: Processor Intel } \\
\text { i3 dengan standar memory RAM } 2 \\
\text { GB. }\end{array}$ & $\begin{array}{l}\text { Pengembangan aplikasi } \\
\text { E-commerce dimulai } \\
\text { dari awal bulan April } \\
2011 \text { dan diperkirakan } \\
\text { selesai pada akhir } \\
\text { September } 2011 .\end{array}$ & $\begin{array}{l}\text { Dapat melakukan penjualan secara } \\
\text { online tanpa adanya batasan waktu } \\
\text { kerja, mampu memberikan informasi } \\
\text { mengenai alat listrik yang dijual secara } \\
\text { lengkap, dan mampu mengelola data } \\
\text { produk yang ditawarkan. }\end{array}$ \\
\hline $\begin{array}{l}\text { E-CRM } \\
\text { (electronic } \\
\text { customer } \\
\text { relationship } \\
\text { management) }\end{array}$ & $\begin{array}{l}\text { Web browser (Google Chrome, } \\
\text { Internet Explorer), aplikasi dengan } \\
\text { bahasa pemrograman PHP, Apache } \\
\text { sebagai web server, dan MySQL } \\
\text { sebagai database. } \\
\text { Sistem operasi: Windows } 7 \\
\text { Professional, Windows Server } \\
\text { Standard 2008. } \\
\text { Spesifikasi hardware: Processor Intel } \\
\text { i3 dengan standar memory RAM }\end{array}$ & $\begin{array}{l}\text { Pengembangan aplikasi } \\
\text { E-CRM dimulai dari } \\
\text { awal bulan Oktober } \\
2011 \text { dan diperkirakan } \\
\text { selesai pada akhir Maret } \\
\text { 2012. }\end{array}$ & $\begin{array}{l}\text { Meningkatkan keuntungan } \\
\text { perusahaan; meningkatkan kinerja } \\
\text { pemasaran untuk jangka waktu yang } \\
\text { panjang; memperluas jangkauan } \\
\text { pelanggan; } \\
\text { E-CRM yang dibuat dapat digunakan } \\
\text { dalam mencapai tingkat kepuasan } \\
\text { pelanggan yang tinggi, sehingga } \\
\text { tercipta hubungan yang baik antara } \\
\text { pelanggan dan perusahaan. }\end{array}$ \\
\hline
\end{tabular}




\begin{tabular}{|c|c|c|c|}
\hline & sebesar 2 GB. & & \\
\hline $\begin{array}{l}\text { Decision } \\
\text { System }\end{array}$ & $\begin{array}{l}\text { Web browser (Google Chrome, } \\
\text { Internet Explorer), aplikasi dengan } \\
\text { bahasa pemrograman PHP, Apache } \\
\text { sebagai web server, dan MySQL } \\
\text { sebagai database. } \\
\text { Sistem operasi: Windows } 7 \\
\text { Professional, Windows Server } \\
\text { Standard 2008. } \\
\text { Spesifikasi hardware: Processor Intel } \\
\text { i3 dengan standar memory RAM } 2 \\
\text { GB. }\end{array}$ & $\begin{array}{l}\text { Pengembangan aplikasi } \\
\text { DSS dimulai dari awal } \\
\text { bulan April } 2012 \text { dan } \\
\text { diperkirakan selesai } \\
\text { pada akhir September } \\
2012 \text {. }\end{array}$ & $\begin{array}{l}\text { DSS memperluas kemampuan } \\
\text { pengambil keputusan dalam } \\
\text { memproses data / informasi bagi } \\
\text { pemakainya; membantu pengambil } \\
\text { keputusan untuk memecahkan } \\
\text { masalah terutama berbagai masalah } \\
\text { yang sangat kompleks dan tidak } \\
\text { terstruktur; menghasilkan solusi } \\
\text { dengan lebih cepat serta hasilnya } \\
\text { dapat diandalkan; menjadi stimulan } \\
\text { bagi pengambil keputusan dalam } \\
\text { memahami persoalannya, karena } \\
\text { mampu menyajikan berbagai } \\
\text { alternatif pemecahan walaupun tidak } \\
\text { mampu memecahkan masalah yang } \\
\text { dihadapi oleh pengambil keputusan. }\end{array}$ \\
\hline $\begin{array}{l}\text { EIS (Executive } \\
\text { Information } \\
\text { System) }\end{array}$ & $\begin{array}{l}\text { Web browser (Google Chrome, } \\
\text { Internet Explorer), aplikasi dengan } \\
\text { bahasa pemrograman PHP, Apache } \\
\text { sebagai web server, dan MySQL } \\
\text { sebagai database. } \\
\text { Sistem operasi: Windows } 7 \\
\text { Professional, Windows Server } \\
\text { Standard 2008. Spesifikasi hardware: } \\
\text { Processor Intel i3 dengan standar } \\
\text { memory RAM } 2 \text { GB. }\end{array}$ & \begin{tabular}{l}
\multicolumn{3}{l}{ Pengembangan } \\
aplikasi EIS dimulai \\
dari awal bulan \\
Oktober 2012 dan \\
diperkirakan \\
pada akhir Maret \\
2013.
\end{tabular} & $\begin{array}{l}\text { Membantu pengambilan keputusan } \\
\text { bagi para eksekutif; merencanakan visi } \\
\text { perusahaan; menentukan kebutuhan } \\
\text { informasi bagi para eksekutif; } \\
\text { melakukan akses cepat untuk ketepatan } \\
\text { informasi dan akses langsung guna } \\
\text { pelaporan manajemen. }\end{array}$ \\
\hline
\end{tabular}

\section{PENUTUP}

Berdasarkan analisis pada lingkungan eksternal dan internal bisnis serta SI/TI perusahaan, dapat disimpulkan bahwa terdapat persaingan yang cukup ketat antar industri, pengaruh lingkungan luar terhadap perusahaan, performa aktivitas dan SI/TI yang belum optimal, adanya kelemahan maupun ancaman yang dapat mempengaruhi kemajuan perusahaan dalam menjalankan bisnisnya. Untuk mengatasi dan meminimalisasi permasalahan-permasalahan tersebut secara bersamaan meningkatkan kekuatan dan peluang yang ada, PT.Tripuri Mitra Nobelindo perlu merencanakan dan menerapkan strategi bisnis, strategi sistem dan teknologi informasi yang tepat guna disesuaikan dengan kebutuhan perusahaan agar efisiensi dan efektivitas proses bisnis serta keunggulan dalam bersaing dapat tercapai sehingga tujuan dan sasaran bisnis perusahaan dapat terpenuhi secara optimal.

Ada beberapa saran yang dapat diusulkan untuk membantu dalam perencanaan strategi sistem dan teknologi informasi pada PT.Tripuri Mitra Nobelindo, antara lain: (1) Untuk mencapai efisiensi dan efektivitas keseluruhan proses bisnis perusahaan serta keunggulan bersaing, disarankan PT.Tripuri Mitra Nobelindo menggunakan pemanfaatan sistem dan teknologi informasi yang tepat guna disesuaikan dengan kebutuhan perusahaan untuk meningkatkan performanya dalam menjalankan bisnis. Dalam mengolah data dan informasi, perlu diterapkan aplikasi DSS dan EIS untuk membantu pihak perusahaan dalam mengambil keputusan. Promosi dan pemeliharaan hubungan dengan pelanggan juga sangat penting bagi perusahaan dalam meningkatkan profit dan keunggulan bersaing, maka perlu diterapkan E-commerce dan E-CRM. Semua aplikasi tersebut harus diintegrasikan secara real time dengan menggunakan aplikasi EAI; (2) Dilakukan pengadaan hardware untuk menunjang aplikasi-aplikasi yang ada untuk beroperasi, seperti pengadaan PC, printer, router, switch dan server serta arsitektur jaringan yang menghubungkan keseluruhan perangkat SI/TI di perusahaan maupun antar kantor cabang; (3) Perlu perencanaan yang baik untuk mengimplementasikan pengembangan website, aplikasi, pengadaan hardware dan arsitektur jaringan yang disesuaikan dengan keterlibatan pihak-pihak terkait sehingga pelaksanaan bisnis perusahaan dapat berjalan sesuai dengan yang diharapkan. 


\section{DAFTAR PUSTAKA}

Jogiyanto, H. M. (2005). Sistem Informasi Strategik (edisi 1). Yogyakarta: Andi.

Ward, John \& Peppard, Joe. (2002). Strategic Plaanning for Information System ( ${ }^{\text {rd }}$ ed.). Chichester: John Willey \& Sons. 